oder auch amorph und dann zerfliesslich. Einige existiren in beiden Formen und sind somit dimorph. Die meisten krystallisirbaren Salze enthalten Krystallwasser. In concentrirten Lösungen werden sie bei $100^{\circ}$ mehr oder weniger rasch zersetzt, ebenso tritt Zersetzung in fester Form bei dieser Temperatur ein. Einige werden schon bei gewöhnlicher Temperatur, wenn auch langsam, zersetzt.

Lund, im März 1879.

\title{
Giebt es Bacterien oder deren Keime in den Organen gesunder lebender Thiere?
}

ron

\section{Nencki und P. Giacosa.}

Unter diesem Titel veröffentlichen die Herren John Chiene und J. Cossar Ewart im Journ. of Anat. and Physiol. (Vol. 13, p. 448, April 1878) Versuche, auf Grund welcher sie die obige Frage mit - noin — beantworten. Wir haben durch die Publication dieser Herren uns veranlasst gesehen, dieselbe einer erneuten experimentellen Prüfung zu unterwerfen, und auf Grund unserer Versuche sagen wir, entgegen den Herren Chiene und Ewart - ja, es giebt Bacterienkeime in den gesunden Geweben lebender Thiere. Dass wir zu diesem Ausspruche berechtigt sind, soll in Folgendem bewiesen werden.

Den Fachgenossen auf diesem Gebiete ist es bekannt, dass der Streit: ob Bacterien, resp. deren Keime in gesunden Geweben lebender Thiere constant vorkommen, nicht neu ist. Es ist namentlich A. Béchamp in Montpellier, welcher in den letzten 20 Jahren in einer Reihe von Publicationen das Vorkommen von Mikrococcen (von ihm Microzymas genannt) in gesunden Geweben lebender Thiere constatirte und ihre Umwandlung im todten Gewebe (en dehors de l'économie) zu Torulaformen und Stäbchen (Bacterien) beschrieb. Nach unserer Ansicht liegt aber das Falsche in den Arbeiten Béchamp's darin, dass er die Coccen (Mikrozymas) als einen nothwen- 
digen Bestandtheil der thierischen Zelle auffasst. Nach ihm bewirken die Mikrozymas die chemischen Processe in den Zellen und sind sogar "faiseurs de cellules". $\mathrm{Zu}$ dieser letzteren Behauptung wurde A. Béchamp veranlasst durch seine später von Pasteur als unrichtig bewiesene Beabachtung, dass aus den Mikrozymas Hefezellen entständen. Béchamp also, weil er eben die Mikrococcen als für die Thierzellen nothwendig auffasste, hat ihren parasitären Charakter verkannt. Deshalb wurden seine häufig unbewiesenen und den herrschenden Vorstellungen widersprechenden Ansichten, namentlich nachdem man ihm Ungenauigkeit im Beobachten nachgewiesen, entweder mit Misstrauen aufgenommen oder auch gänzlich ignorirt. Es hiesse jedoch das Kind mit dem Bade ausschütten, wollte man die verschiedenen in Montpellier angestellten und durch die Theorien Béchamp's veranlassten Arbeiten unbeachtet lassen. So finden wir in dem von Joseph Béchamp herausgegebenen Buche: „Les Microzymas. Montpellier et Paris 1875, p. 22" auch die Angabe, dass M. Servet, préparateur de M. Estor, a fait dans le laboratoire de ce professeur l'expérience suivante: Des organes divers, pris sur le vivant, sont plongés dans une solution d'acide chromique, c'est à dire dans un milien où rien ne peut vivre, et examinés quelques temps après. La surface durcie laisse apercevoir les tissus normaux inaltérés; l'intérieur de ceux-ci protégés à la fois par la dissolution d'acide chromique et par la surface coagulé de l'organe, des bactéries à divers degrés de développement.

Unabhängig von den französischen Experimentatoren und hauptsächlich zu ihren Untersuchungen durch die Doctrinen der neueren Pathologie veranlasst, haben in Deutschland Billroth und Tiegel ${ }^{1}$ ) die These vertheidigt, dass im Gewebe und Blute lebender gesunder Thiere Spaltpilzkeime vorhanden seien. Die Versuchsanordnung Tiegel's war folgende: Die zu untersuchenden Organe oder durch einen glatten Messerschnitt getrennte Stücke derselben wurden einem eben getödteten, meist durch die Carotis entbluteten Thiere

i) Virchow's Archiv 60, 453. 


\section{Nencki u. Giacosa: Giebt es Bacterien oder}

entnommen, möglichst rasch an einen vorher gut ausgekochten Seidenfaden gebunden und in $110-115^{\circ}$ heisses, geschmolzenes Paraffin, je nach der Grösse des Stückes längere oder kürzere Zeit eingetaucht. Nachdem das an der Oberfläche haften gebliebene Paraffin erkaltet war, wurde das Eintauchen wiederholt, das Präparat jedoch sehr rasch wieder herausgenommen, um die anbaftende Paraffinkruste nicht wieder abzuschmelzen. Nur in der Absicht, die Paraffinkruste zu verstärken, wurde das Eintauchen noch einige Male wiederholt. Nachdem auch die letzte Schicht erkaltet war, wurde das ganze Präparat in eine grössere, eben im Erstarren begriffene (52 warme) Paraffinmasse versenkt und mit dieser erkalten gelassen. Die so erhaltenen Klötze wurden nach ihrem Erkalten eine bestimmte Zeit lang bei Temperaturen von etwa $30^{\circ}$ aufbewahrt, dann zerschlagen und ihr Inhalt untersucht. Das starke Brühen der Organe sollte die von Aussen her auf die Oberfläche aufgefallenen Keime zerstören, und anch solche, die möglicherweise in der Zeit von der Eröffnung des Thieres bis zum Brühen schon bis zu einer gewissen Tiefe in das Organ eingedrungen sind. Es wurde nun folgendes allgemeine Resultat gewonnen. In Pankreas, Leber, Milz, Speicheldrüsen; Hoden, im Muskelfleisch und im Blut können sich, wenn die Klötze in einer Temperatur zwischen $20-30^{\circ}$ gestander haben, in der angegebenen Zeit von 4-12 Tagen Bacterien entwickelt haben. Am häufigsten ist dies der Fall mit dem Pankreas und finden sich in ihm auch verhältnissmässig die meisten Bacterien; am seltensten und in der geringsten Anzahl finden sie sich im Blute vor.

Obgleich Tiegel den Einwand, dass beim Erkalten der Paraffinklötze sich Risse und Sprünge bilden, wodurch das Eindringen von Bacterien aus der Luft ermöglicht wäre, berücksichtigte und ihn zu umgehen suchte (siehe S. 464 seiner Abhandlung), so wird doch dieser Umstand von den Mikrographen immer von Neuem als gegen die Zuverlässigkeit der Tiegel'schen Versuche sprechend, erhoben. ${ }^{1}$ ) Wir

1) Koch, Aetiologie d. Wundinfectionskrankheiten. Leipz. 1878. 
wollen deshalb hier hervorheben, dass Dr. Burdon Sanderson $\left.{ }^{1}\right)$ die Tiegel'schen Versuche in der Weise wiederholte, dass das herausgenommene Organ sofort in auf $110^{\circ}$ erhitztes Paraffin hineingeworfen wurde. Sobald die Masse erstarrte, wurde die Oberfläche mit venetianischem Terpentin bedeckt, um gegen die Möglichkeit der Inficirung, die beim Zerbersten der sich abkühlenden Paraffinoberfläche geschehen könnte, zu schützen. In einigen Versuchen wurde Oel bei der gleichen Temperatur als Ersatzmittel für das Paraffin angewendet. Burdon Sanderson giebt an, dass wenn nach 1-2 Tagen das zu Boden des Gefässes gefallene Organ aus dem Paraffin herausgenommen wird, die Oberfläche desselben in Folge der Hitze geronnen ist. Der centrale Theil aber hatte die blassrothe Farbe des ungekochten Gewebes und enthielt reichlich Bacterien in den verschiedenen Stadien ihrer Entwicklung.

Hauptsächlich nun deshalb, weil die antiseptische Methode Lister's der Wundbehandlung so ausgezeichnete Erfolge aufzuweisen hat, war es den Herren J. Chiene und Cossar Ewart, trotz der Versuche Tiegel's und Sanderson's, nicht wahrscheinlich, dass die gesunden Organe lebender Thiere Bacterienkeime enthalten könnten. Nach Lister's Verfahren wird bekanntlich jede chirurgische Operation unter Verstäubung einer 5proc. Phenollösung ausgeführt. Die letztgenannten Autoren gingen daher von der Voraussetzung aus, dass in der Zeitdauer zwischen Herausnahme des Organs und Eintauchen in Paraffin Bacterienkeime aus der Luft auf die Gewebe fallen und so nachher die Fäulniss bewirken können. Dies sollte durch Anwendung des antiseptischen Verfahrens verhütet werden. Ihre Versuchsanordnung war daher folgende: Unter fortwährendem Verstäuben einer 5 proc. Phenollösung wurde einem soeben getödteten Kaninchen die Bauchhöhle geöffnet und die Leber, Milz, Nieren und Pankreas herausgenommen. Die Leber wurde in mehrere Stücke zerschnitten, einige Stücke in antiseptische (d. h. in Phenollösung getränkte), andere dagegen

1) British Medical Journal, Jan. 26, 1878. 


\section{Nencki u. Giacosa: Giebt es Bacterien oder}

in unpräparirte Gaze gewickelt; wieder andere wurden in ansgeglühte Gefässe gethan, welche entweder durch Wolle, Gaze oder Glasdeckel beschïtzt wurden. Achnlich verfuhr man mit den anderen Organen. Nach drei Tagen wurden die Organe untersucht und es zeigte sich, dass in all den Theilen, die in antiseptische Gaze gewickelt waren, keine Spur von irgend welchen ausgebildeten Bacterien zu finden war. Isolirte, bewegliche Körnchen waren zahlreich vorhanden, ihre Bewegung war aber eine einfach moleculare (Brownian nature). Die Herren Chiene und Ewart ziehen daher den Schluss, dass wenn die Organe angenblicklich nach dem Tode mit antiseptischen Vorsichtsmaassregeln behandelt werden, dann keine Spur ron Bacterien zu finden sei; folglich auch weder Bacterien, noch deren Keime in den gesunden Organen der Thiere während des Lebens bestehen. Ist num dieser Schluss berechtigt? Hindert das Einwickeln in die antiseptische Gaze auch nicht die Entwicklung der in den Geweben selbst enthaltenen Bacterienkcime?

Wir haben folgende Versuche angestellt:

In einem Becherglase von etwa $1 / 2$ Liter Inhalt wurde leichtflüssige, bei $75^{\circ}$ sclmelzende Metallegirung (Wood'sches Metall) auf $300-400^{\circ}$ erhitzt. Sobald die Legirung auf etwa $150^{\circ}$ erkaltete, wurde darauf eine Schicht 5 proc. Phenollösung vorsichtig gegossen und durch Einstellen des Gefässes in kochendes Wasserbad das Metall flüssig erhalten. Hierauf wurde einem Kaninchen, dem vorher die Bauchwand geschoren und mit Phenollösung abgewaschen war, unter Phenolstäuben (5 proc. Lösung) die Bauchhöhle geöffnet, ein grösseres Stück Leber herausgeschnitten, dasselbe mit einer Pincette gefasst, in die Wood'sche Legirung eingetaucht und so lange hinabgedrückt, bis das erkaltende Metall fest um das Gewebe und die Pincette erstarrte. Sodann liessen wir das Ganze bis zu 4 Tage lang bei $40^{\circ}$ stehen. Dass das Metall beim Erstarren Sprünge oder Risse bekommen würde, war nicht zu befürchten; aber anch für den Fall befand sich über dem Metall ununterbrochen eine 3-5 Ctm. hohe Schicht einer concentrirten Phenollösung, die jedes Eindringen von Keimen aus der Luft unmöglich gemacht 
haben würde. Eine höchst einfache und nicht minder tadellose Versuchsanordnung war folgende: Ein grösseres, eisenemaillirtes Gefäss $(a)$ (siehe beistehende Zeichnung) wurde bis zu zwei Drittel mit reinem Quecksilber gefüllt. Hierauf wurde ein $5 \mathrm{Ctm}$. weites Glasrohr, dessen eines Ende rund zugeschmolzen, das andere aber offen und glatt abgeschliffen war, ebenfalls mit reinem Quecksilber gefiillt, mit einer

Glasplatte geschlossen und in das Gefäss (a) eingetancht, hierauf das Ganze erhitzt, bis das Gefäss (b) etwa

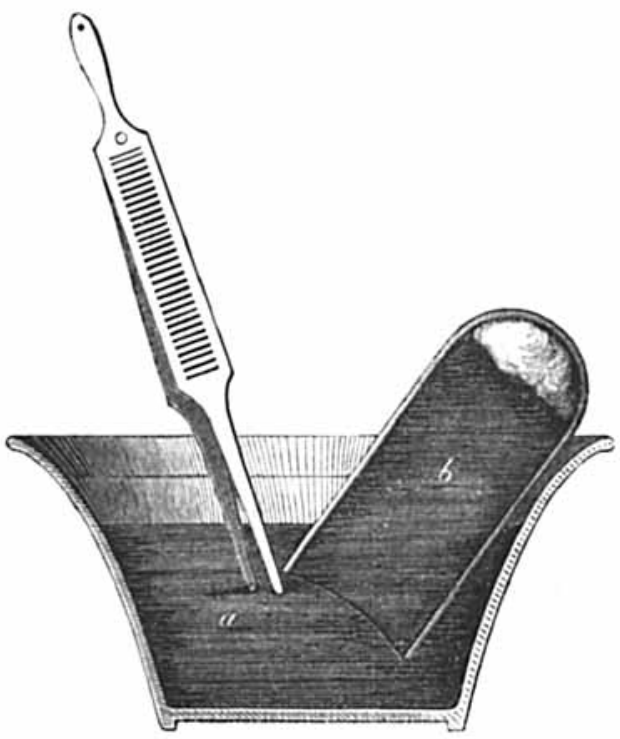

bis zu einem

Dritttheil mit Quecksilberdampf erfült war. Wenn demnach irgend welche Bacterienkeime in dem Cylinder $(b)$ enthalten gewesen wären, müssten sie sicher durch das siedende Quecksilber zerstört worden sein. Man liess nun erkalten, wobei sich das Quecksilber wieder in dem Cylinder (b) condensirte, und als die Temperatur in dem Aussengefässe etwa $120^{\circ}$ hatte, wurde es mit einer 5 proc. Phenollösung übergossen. Unter den gleichen Cautelen und Anwendung des ganzen antiseptischen Apparates wurde irgend ein inneres Organ einem soeben getödteten Kaninchen (Leber, Herz, Niere, Milz) entnommen und mit einer Pincette in das für den Moment etwas schief geneigte Gefäss (b) geführt, wo es nach oben stieg und daselbst verblieb. Der Apparat wurde dann ebenfalls ein bis mehrere Tage lang bei $40^{\circ}$ stehen gelassen. 


\section{Nencki u. Giacosa: Giebt es Bacterien oder}

Das Ergebniss von auf die eine oder andere oben angeführte Weise angestellten Versuchen war immer zu Gunsten der Annahme, dass in dem gesunden Gewebe lebender Thiere Bacterien enthalten sind. Schon nach 24 stündigem Stehen bei $40^{\circ}$ zeigten alle die untersuchten Organe, wie Leber, Niere, Milz, Herz intensiv fauligen Geruch und unzählige Spaltpilze in verschiedensten Formen. Besonders geeignet zur Demonstration dieser. Thatsache ist die Versuchsanordnung mit dem Quecksilbergefäss. $\mathrm{Da}$ das $\mathrm{Hg}$ unter der schützenden Phenolschicht bis auf $40^{\circ}$ abgekühlt werden kann, so verliert das eingetauchte Organ kein Wasser, und auch die in ihm enthaltenen Bacterienkeime werden nicht zerstört, wie das theilweise bei den Versuchen mit Paraffin und Wood'schem Metall der Fall ist. Der Beginn der putriden Zersetzung wird durch die Gasentwicklung angezeigt, welche das Quecksilber herunterdrückt. Bei Organen, wie Pankreas und Leber, stellt sich die Fäulniss mit der gleichen Präcision ein, wie wenn diese Organe an der Luft in offenen Gefässen ständen. Bei den Nieren haben wir den Beginn der Gasentwicklung schon in der zehnten Stunde, beim Herzen erst in der achtzehnten Stunde gesehen.

Auch beim Einschmelzen der Organe in Wood'sches Metall stellt sich die Fäulniss regelmässig ein, vorausgesetzt, dass das Organ nicht zu klein war. Als wir nach 2-3 Tagen das Metall auf dem Sandbade wieder schmolzen, waren die Gewebe, wie z. B. Leber, Niere, mit verschiedenen Formen lebhaft beweglicher Spaltpilze ertüllt. Kleinere Organe, wie Kaninchenpankreas oder Niere, eignen sich zu diesen Versuchen nicht; denn obgleich wir nach dem Eintauchen der Milz das Metall möglichst rasch abkühlten, so fanden wir doch beim Aufschmelzen der Legirung das Organ ganz durchkocht und folglich auch keine Bacterien. Da die Herren Chiene und Ewart das negative Ergebniss ihrer Versuche der Anwendung der antiseptischen Methode zuschreiben, so halten wir es für nöthig, hervorzuheben, dass in unseren Versuchen dem Lister'schen Verfahren volle Rechnung getragen wurde. Alle zu den Versuchen verwendeten Gefässe wurden vorher mit 5 proc. Phenollösung ab- 
gewaschen; ebenso wurden die Instrumente direct aus einer 5 proc. Phenollösung herausgenommen. Prof. Kocher, Director der hiesigen chirurgischen Klinik, der an diesen Versuchen lebhaften Antheil nahm, hat bäufig die Herausnahme der Organe und Eintauchen derselben, sei es in Wood'sches Metall oder unter Quecksilber, genau wie bei einer chirurgischen Operation nach Lister's Methode besorgt. Weshalb ist denn aber die Fäulniss in den Versuchen der Herren Chiene und Ewart ausgeblieben? Dass weder Verstäuben, noch eine momentane Berührung mit Phenollösung die Keime in den Geweben gänzlich tödtet, geht aus unseren Versuchen hervor, wo die Organe durch die Phenollösung hindurch in Wood'sches Metall, oder unter Quecksilber eingebracht wurden und doch Bacterienentwicklung und übler Geruch eingetreten sind. Anders verhält es sich wohl, wenn das Bacterienkeime enthaltende Organ längere Zeit hindurch mit einem mit Phenollösung getränkten Gegenstande in directer Berührung bleibt. Prof. Kocher hat die Versuche der Herren Chiene und Ewart wiederholt und ihre Resultate bestätigt gefunden. Es wurde unter Phenolverstäubung z. B. Leber einem frisch getödteten Kaninchen entnommen und in Phenolgaze, sodann Watte, schliesslich Transparentleinwand eingewickelt und bei $40^{\circ} 2$ Tage lang gehalten. Nach Verlauf dieser Zeit zeigte die Leber keine Fäulniss, weder Bacterien, noch üblen Geruch. Als wir aber die Leber, die einen schwachen Geruch nach Phenol besass, mit etwas Wasser abspülten und das filtrirte Spülwasser durch Erlitzen bis zum Sieden enteiweissten, so gab das eiweissfreie Filtrat, mit Bromwasser versetzt, einen reichlichen Niederschlag von Tribromphenol. - Weshalb also in diesem Falle die Fäulniss ausgeblieben ist, war klar. Wir wiederholten den Versuch vollkommen ceteris paribus, nur mit dem einzigen Unterschiede, dass die herausgenommene Leber, statt direct in Phenolgaze eingewickelt $\mathrm{zu}$ werden, zwischen zwei genau auf einander passende Uhrgläser, die rorher in Phenollösung lagen, und damn über freier Flamme rasch getrocknet wurden, gebracht wurde. Nach 2 Tagen waren in der Leber neben Coccen und Streptococcen Stäbchen und 


\section{Nencki u. Giacosa: Giebt es Bacterien oder}

Köpfchenbacterien vorhanden. Damit dieser letzte Versuch gelingt, ist es nothwendig, dass die Uhrgläser nicht zu klein und gut auf einander geschliffen sind.

Die Herren Chiene und Ewart führen einen Versuch an, wo sie in eine Niere durch die Nierenarterie eine bacterienhaltige Iösung einspritzten, und in antiseptische Gaze einwickelten. In dieser Niere fand Fäulniss statt. Dieser Versuch kann aber eigentlich nicht als Controlversuch gelten, denn zur Tödtung bereits entwickelter Bacterien sind jedenfalls grössere Mengen Phenol nöthig, als wie zur Abhaltung der Entwicklung von in Geweben enthaltenen Keimen.

Es ergiebt sich hieraus, dass obgleich die Bacterienkeime in den Geweben lebender Thiere constant vorkommen, die antiseptische Wundbehandlung durchaus begründet ist. Unser Verständniss der ausgezeichneten Erfolge des Lister'schen Verfahrens wird dadurch nur klarer, demn wir finden, dass nicht allein durch das Verstäuben des Phenols während der Operation und durch Anlegen des antiseptischen Verbandes die in der Iuft vorhandenen Keime abgehalten werden, sondern dass auch durch Imbibition der Wunde von dem Verbande aus mit cler fäulnisswidrigen Substanz die im Gewebe selbst enthaltenen Keime unschädlich gemacht werden.

Untersucht man bei starken Vergrösserungen die Gewebe, z. B. Leber oder Pankreas soeben getödteter Thiere, so findet man um die Zellen herum in grosser Menge kleine Kügelchen von $0,5-2$ Mikrometer im Durchmesser. Sie wurden früher „körniger Detritus" genannt. In dem Buche von Béchamp sind diese Körnchen abgebildet und als Mikrozymas bezeichnet. Wie der eine von uns $^{1}$ ) schon früher hervorgehoben hat, finden sich jedoch in frischen, gesunden Geweben keine entwickelten Formen der Spaltpilze, wie etwa Stäbchen oder Ketten von Coccen oder Bacterien. Erst 2-4 Stunden nach dem Tode werden die Torulaformen und noch später die cylindrischen Stäbchen sichtbar. Wir

1) M. Nencki: Ueber die Zersetzung der Gelatine und des Eiweisses bei der Fäulniss mit Pankreas. Bern 1876. S. 35 . 
sind deshalb geneigt anzunehmen, dass in den gesunden Geweben lebender Thiere nicht fertig entwickelte Bacterien, sondern vorwiegend deren Keime (Sporen) enthalten seien. Wenn aber aus kleinen Kügelchen (Sporen) sich später Stäbchen entwickeln, so ist damit nicht gesagt, dass sie alle als Sporen von Mikrobacterien oder Bacillen zu betrachten seien. Vor Kurzem ${ }^{1}$ ) hat der eine von uns aus einem eitrigen, pleuritischen Exsudat die charakteristischen Fäulnissprodukte, wie Indol und Phenol dargestellt, während die in dem Eiter rorhandenen Organismen einzig und allein durch die Kügelchen von $0,5-1$ Mikrometer im Durchmesser repräsentirt waren. Eine Unterscheidung zwischen den Mikrococcen und den als Sporen der Stäbchen zu betrachtenden Kügelchen ist vorläufig nicht möglich:

In unseren Versuchen betrug die Zeitdauer von der Eröffnung der Leibeshöhle des Kaninchens bis zum Eintauchen der Leber unter Quecksilber oder Wo od'sches Metall nur 20-30 Secunden. Es ist schon deshalb höchst unwahrscheinlich, dass die nachher eingetretene Fäulniss durch Anfliegen von in der Luft enthaltenen Keimen bewirkt worden sei. Wäre dies der Fall, so müsste in der That die Luft mit Bacterien und ihren Keimen in einer Weise erfullt sein, wie dies unseren bisherigen Erfahrungen gänzlich widerspricht. Es wäre dann vollständig unbegreiflich, dass bei einer derartigen Verbreitung der Spaltpilze und deren Keime gerade unsere Gewebe frei davon sein sollten. Wir haben absichtlich unsere Versuche in einem Zimmer ausgeführt, in welchem gar keine Untersuchungen über Spaltpilze angestellt werden; auch die Kaninchen wurden nicht im Laboratorium gehalten, sondern stets frisch vom Markt zu den Experimenten geholt. Direct angestellte Versuche zeigten, dass in unserem Laboratorium, wo seit Jahren ununterbrochen Untersuchungen über Fäulniss angestellt werden, die Luft mehrere Stunden dureh eine Nährlösung geleitet werden musste, ehe dieselbe mit Fäulnissbacterien inficirt wurde. ${ }^{2}$ )

1) Dies. Journ. [2] 19, 355.

2) Vgl. anch F. Ćohn, Beiträge zur Biologie der Pflanzen. I. Bd. 3. Heft, S. 147. 
44 Tornöe: Resultate d. norweg. Nordmeerexpedition.

In der Wissenschaft haben sich die Theorien nach den Thatsachen zu richten und nicht umgekehrt. Die Doctrinen der Pathologie müssen die Thatsache, dass die gesunden Gewebe lebender Thiere Bacterienkeime enthalten, anerkennen und sie beim Forschen nach den Ursachen der Infectionskrankheiten in Betracht ziehen. Es ist uns übrigens unverständlich, weshalb die Vertheidiger des „contagium vivum" sich so sehr gegen die Anerkennung dieser Thatsache sträuben. Das Vorkommen der Keime gewöhnlicher Fäulnissbacterien beweist nicht, dass bestimmte pathogene Spaltpilze in den gesunden Geweben enthalten seien. Im Gegentheil, erst dadurch, dass es bewiesen ist, dass die Keime der gewöhnlichen Fäulnissbacterien in gesunden Geweben constant vorkommen, gewinnt die Ansicht, dass die Ursache verschiedener Infectionskrankheiten gewisse Formen der Spaltpilze sind, eine positive Basis. Denn wenn man weiss, dass die gewöhnlichen Fäulnissbacterien von den Athmungsund Verdauungswerkzeugen aus in die sämmtlichen Grewebe unseres Organismus eindringen können, so ist die Lehre vom "contagium vivum" nur eine nothwendige Consequenz davon.

Bern, im Juni 1879.

\section{Resultate der norwegischen Nordmeerexpedition; \\ von}

Heroules Tornöe.

\section{Ueber die Kohlensäure im Seewasser.}

Von allen Chemikern, welche vor der im Jahre 1872 ausgesendeten Pommeraniaexpedition Untersuchungen über die Luft im Seewasser angestellt haben, wurden neben der Bestimmung der Sauerstoff-Stickstoffmenge auch noch Messungen der bei dem Auskochen ausgetriebenen Kohlensäure angestellt; die auf diese Weise gefundenen Werthe wurden auch regelmässig unter den Resultaten als gesammte Menge 